\title{
KOMPOSISI MAKANAN DALAM LAMBUNG TERIPANG
}

\author{
Anita Padang*, Erika Lukman* dan Madehusen Sangadji* \\ * Staf Pengajar FKIP UNIDAR-Ambon, e-mail: -
}

\begin{abstract}
ABSTRAK
Teripang merupakan salah satu kelas dari filum Echinodermata, dimana tubuh teripang bertekstur lunak, berdaging, berbentuk silindris memanjang seperti ketimun sehingga hewan ini sering disebut ketimun laut. Teripang merupakan organisme bentos yang cara makannya deposit feeding yaitu mengkonsumsi makanan yang tersimpan atau terdeposit dalam sedimen. Penelitian ini bertujuan untuk mengetahui komposisi jenis makanan dalam lambung teripang sehingga dapat diaplikasikan dalam usaha pemeliharaan teripang. Penelitian dilakukan dengan mengkoleksi sampel teripang secara bebas pada perairan intertidal Desa Suli pada bulan Maret 2014, kemudian dilanjutkan dengan mengidentifikasi jenis makanan dalam lambung teripang pada laboratorium biologi Universitas Darussalam Ambon pada bulan April 2014. Hasil penelitian terhadap 26 ekor teripang yang terdiri dari 6 jenis yaitu Holothuria scabra, Holothuria atra, Holothuria nobilis, Holothuria axiologa, Bohadschia marmorata dan Bohadcshia graeffei, ditemukan adanya komposisi makanan dalam lambung teripang yaitu fitoplankton dan zooplankton. Komposisi terbesar dalam lambung teripang adalah fitoplankton kelas Diatom/Baccilariophyceae sebesar 56\% yang terdiri dari 23 genus.
\end{abstract}

Kata Kunci: Teripang, Intertidal, Lambung, Diatom

\section{PENDAHULUAN}

Teripang adalah salah satu kelas dari phylum Echinodermata yaitu Holothuroidea yang dapat dimakan. Teripang adalah hewan yang bergerak lambat (semi mobile), hidup pada dasar substrat pasir, lumpur berpasir maupun dalam lingkungan terumbu karang dan lamun. Ketersediaan teripang di perairan sangat tergantung terhadap ketersediaan makanan pada substratnya. Sutaman (1993) mengemukakan bahwa teripang umumnya merupakan pemakan deposit yang kaya akan unsur hara dengan sumber makanannya adalah diatom, protozoa, nematoda, copepoda, ostrakoda serta filamen alga dan lamun.

Teripang memiliki nilai ekonomis yang cukup baik misalnya teripang pasir (Holothuria scabra) di pasar domestik nilai jual teripang pasir kering sebesar Rp. $750.000,-/ \mathrm{kg}$, hal ini menyebabkan teripang pasir terus dieksploitasi. Tingginya tingkat eksploitasi terhadap teripang, maka dikhawatirkan akan berkurang populasinya di alam. Guna mengatasi berkurangnya populasi teripang di alam, maka perlu dilakukan usaha budidaya teripang, dimana pakan merupakan unsur penting dalam menjamin keberhasilan usaha budidaya tersebut, khususnya budidaya teripang yang dilakukan oleh masyarakat nelayan secara alami di habitat aslinya.

Dengan mengetahui makanan alaminya di alam maka sangat mudah dalam aplikasi budidaya sebagaimana dikemukakan oleh Effendie (2002) bahwa untuk mengetahui makanan yang tersedia di alam (habitat) dan dimanfaatkan oleh ikan, dapat dilakukan dengan mengambil contoh makanan yang ada pada lambungnya. Hal yang sama tentunya dapat dilakukan terhadap teripang dengan menganalisa isi lambungnya. Dengan demikian tujuan penelitian ini adalah mengetahui jenis makanan apa saja yang ada dalam lambung teripang, yang dapat diaplikasikan dalam pemeliharaan teripang dalam rangka budidaya. 
II. Metode Penelitian

Penelitian dilaksanakan pada bulan Maret-April 2014, diawaili dengan pengambilan sampel teripang pada daerah intertidal perairan Desa Suli secara koleksi bebas. Desa Suli memiliki posisi geografis terletak pada $1^{128^{01}} 7^{\prime 2} 6^{\prime \prime}$ BT-128 ${ }^{01} 8^{\prime} 15^{\prime \prime B T}$ dan 03037'00"LS-03 ${ }^{03} 8^{\prime} 19^{\prime \prime}$ LS.

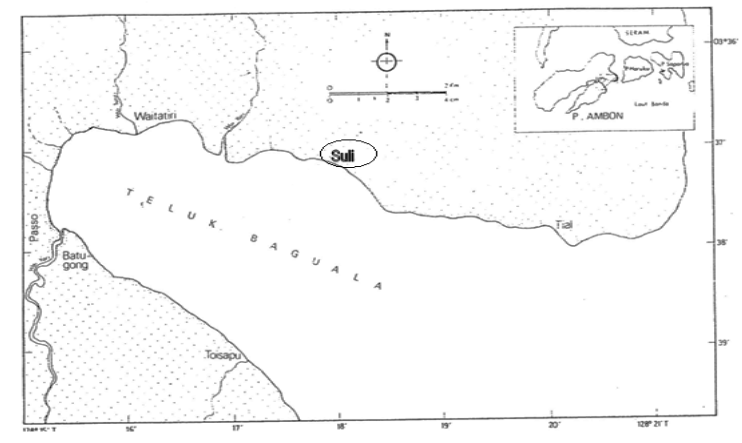

Gambar 1. Peta Lokasi Penelitian

$$
\text { Keterangan: } \begin{array}{r}
\text { Lokasi Penelitian } \\
\text { Sumber:LIPI } 2008
\end{array}
$$

Penelitian dilanjutkan dengan menganalisa isi lambung teripang di laboratorium biologi Universitas Darussalam Ambon.

Analisa isi lambung teripang dimulai dengan menggunting perutnya mulai dari bagian anterior sampai posterior untuk diambil lambungnya. Selanjutnya isi lambung dikeluarkan dan dimasukan ke dalam wadah yang telah diberi formalin $4 \%$. Isi lambung teripang yang telah diberi formalin sebagai bahan pengawet diambil dengan pipet $1 \mathrm{ml}$ dan diletakkan pada haemocytometer untuk diamati dengan menggunakan mikroskop Olympus pembesaran 400 kali. Identifikasi isi lambung teripang berdasarkan buku Yamaji (1966), Newel and Newel (1977), Tomas (1997) dan Van Heurck (1962).

Analisis isi lambung teripang meliputi beberapa analisis :

a. Komposisi diatom bentik dalam lambung teripang dan sedimen didasarkan pada formula menurut Fachrul (2007) :

$$
\text { Komposisi (\%) }=\frac{\sum \text { individu suatu jenis }}{\sum \text { individu semua jenis }}
$$

b. Menganalisa kebiasaan makan teripang digunakan metode frekuensi kejadian (Effendie, 1979) sebagai berikut:

$$
\mathrm{Fr}=\frac{\mathrm{Li}}{\mathrm{Lt}} \times 100 \%
$$

Dimana :

Fr $=$ Frekuensi kejadian satu macam makanan

Li = Jumlah makanan per jenis dalam organ pencernaan

Lt $=$ Jumlah total organ pencernaan yang berisi makanan

c. Hubungan Jumlah Lambung dengan Makanan-Jumlah Total Lambung berdasarkan (Romimohtarto dan Juwana, 2007) sebagai berikut :

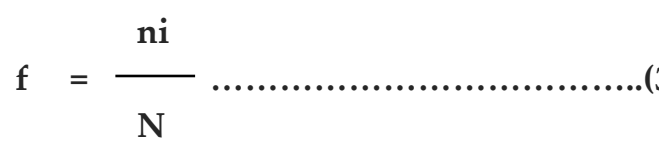

Dimana :

ni = Jumlah lambung dengan makanan " $i$ "

$\mathrm{N}=$ Jumlah total lambung yang dianalisa

d. Hubungan Jumlah Makanan-Jumlah Total Makanan Dalam Lambung berdasarkan (Romimohtarto dan Juwana , 2007) sebagai berikut :

$$
\mathrm{Cn}=\frac{\mathrm{ni}}{\mathrm{Np}}
$$

Dimana :

ni = Jumlah makanan "i"

$\mathbf{N}=$ Jumlah total makanan dalam lambung

\section{Hasil dan Pembahasan}

3.1.Komposisi Makanan di Lambung Teripang

Teripang yang dikoleksi di perairan intertidal desa Suli sebanyak 26 ekor, berdasarkan identifikasi morfologi serta spikula teripang, terdiri dari 6 jenis yaitu Holothuria scabra, Holothuria atra, Holothuria nobilis, Holothuria axiologa, Bohadschia marmorata dan Bohadcshia graeffei. Keenam jenis teripang ini mengkonsumsi makanan yang tersedia pada substrat dengan cara makan secara deposit feeding tanpa memilih jenis makanan. Hal ini terlihat dengan hasil penelitian yang memperlihatkan jenis makanan dalam lambung teripang terdiri dari 
fitoplankton kelas Diatom, Cyanophyceae, Dinoflagellata dan Clorophyceae serta zooplankton yang terdiri dari telur, larva, Nauplius, Copepoda, Brachionus, Daphnia dan Foraminifera. Pemanfaatan jenis makanan yang tersedia pada substrat oleh teripang juga ditemukan oleh Yusron dan Syafei (1997) serta Hartati dkk (2004).

Komposisi jenis makanan dalam lambung teripang dengan komposisi terbesar adalah fitoplankton diatom yaitu sebesar $56 \%$ yang terdiri dari 23 genus. Komposisi makanan dalam lambung teripang dapat dilihat pada gambar di bawah ini.

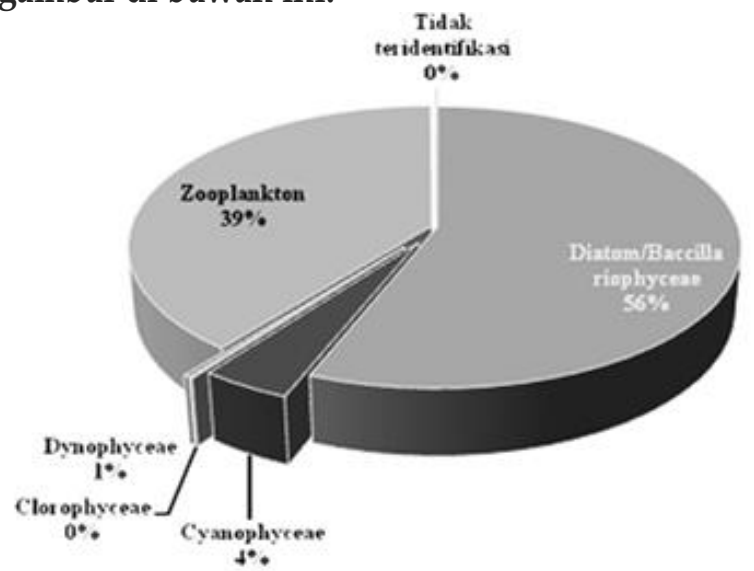

Gambar 1. Komposisi Makanan dalam Lambung Teripang

\subsection{Frekuensi Kejadian}

Frekuensi makanan dalam lambung teripang yang dianalisa sebanyak 26 ekor lebih didominasi oleh kelompok Diatom sebesar $78 \%$. Hal yang sama juga ditemukan oleh Yusron dan Syafei (1997) yang juga menemukan Diatom sebagai kelompok dengan frekuensi terbesar dalam lambung teripang.

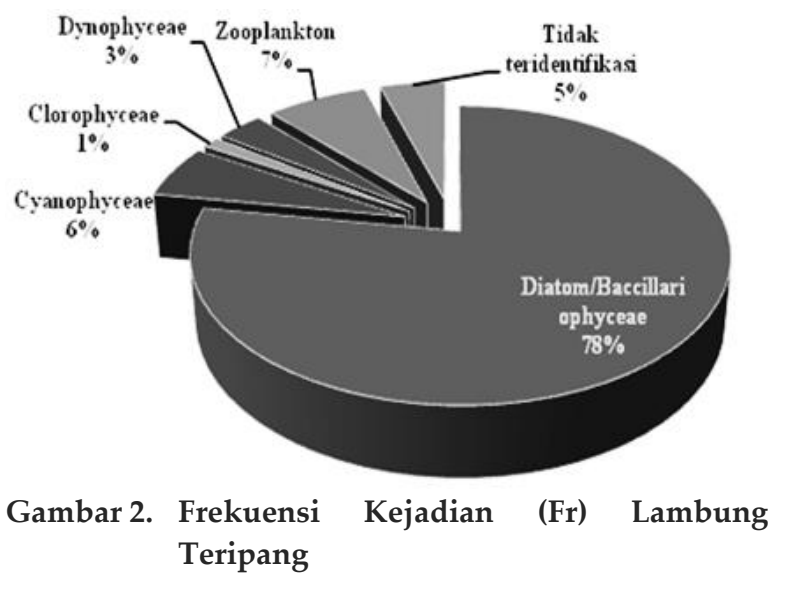

Dengan tingginya frekuensi Diatom dalam lambung teripang memperlihatkan bahwa teripang sebagai organisme deposit feeding, sangat tergantung terhadap ketersedian makanan di habitatnya. Diatom bentik dari ordo pennales yang lebih mendominasi substrat tempat hidupnya teripang, tentunya akan dikonsumsi oleh teripang dan organisme bentos lainnya yang cara makannya deposit feeding seperti Haliotis asinina (Sofyan $d k k$, 2005).

\subsection{Hubungan Jumlah Lambung dengan Makanan}

Dari 26 lambung yang dianalisa ditemukan ternyata makanan yang lebih banyak dikonsumsi oleh teripang di lokasi penelitian adalah Diatom dengan presentasi sebesar $84 \%$ kemudian diikuti oleh zooplankton sebesar $10 \%$. Hal ini memperlihatkan bahwa Diatom merupakan kelompok makanan yang banyak dikonsumsi oleh teripang, karena Diatom mempunyai peranan sebagai penyumbang produktivitas perairan lingungan bentik (Padang, 2012).

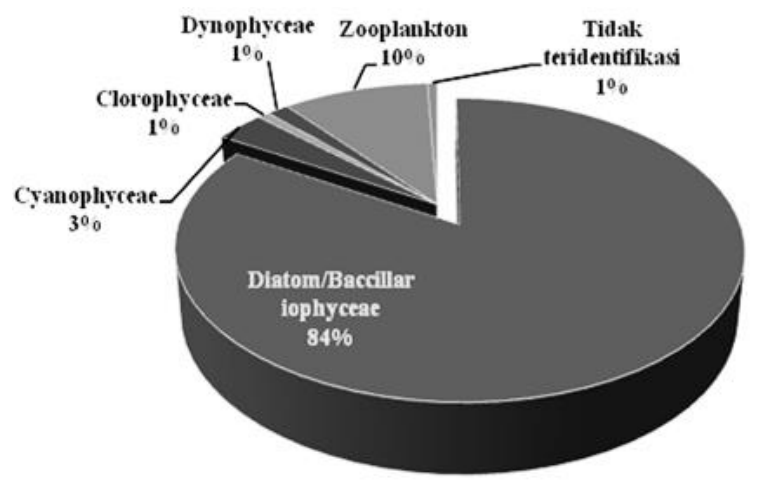

Gambar 3. Hubungan Jumlah Lambung Teripang dengan Makanan (f)

Selain Diatom ternyata zooplankton juga banyak terdapat dalam lambung teripang, zooplankton sebagai organisme konsumer pertama. Zooplankton yang ditemukan terdiri dari kelompok holoplankton (zooplankton sejati/seumur hidupnya sebagai plankton) antara lain Nauplius, Copepoda, Brachionus, Foraminifera dan Daphnia serta kelompok meroplankton (sebagian hidupnya dilalui sebagai plankton) yaitu larva organisme bentos dan nekton. Khususnya bagi larva organisme 
bentos yang melakukkan aktifitas settlement guna menjadi juvenil.

\subsection{Jumlah Makanan dengan Jumlah Total Makanan Dalam Lambung}

Ternyata jumlah makanan yang lebih banyak dalam 26 lambung teripang yang dianalisa adalah zooplankton sebesar $56 \%$ yang terdiri dari (larva, telur, Nauplius, Copepoda, Brachionus, Daphnia dan Foraminifera) kemudian Diatom sebesar $43 \%$. Diatom merupakan kelompok fitoplankton terbesar yang berada dalam lambung teripang jika dibandingkan dengan Cyanophyceae, Dinoflagellata dan Clorophycea.

Tidak

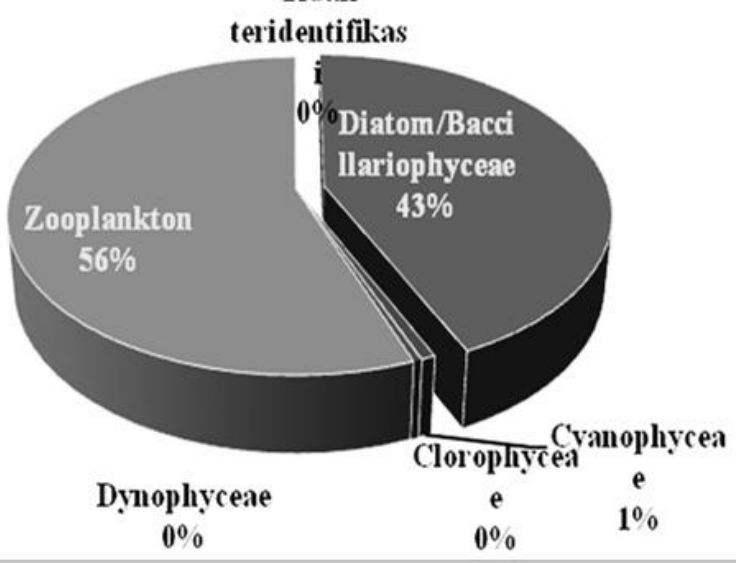

Gambar 4. Hubungan Jumlah Makanan dengan Jumlah Total Makanan Dalam Lambung (Cn)

Diatom terdiri dari dua ordo yaitu ordo pennales dan ordo centrales, dimana komunitas bentik lebih didominasi oleh ordo pennales (Sumich, 1999). Sebagaimana hasil penelitian Huliselan (2002) di pantai Naku; Padang di perairan Teluk Ambon Dalam (2009); Padang (2010) di perairan intertidal Suli dan Padang
(2011) di perairan intertidal desa Tulehu yang menemukan ordo pennales lebih mendominasi wilayah bentik dibandingkan ordo centrales. Sehingga diatom ordo pennales merupakan makanan bagi organisme makrobentos yang cara makannya deposit feeding seperti teripang.

Jenis makanan pada 5 jenis teripang yang ditemukan yaitu Holothuria atra, Holothuria nobilis, Holothuria axiologa, Bohadschia marmorata dan Bohadcshia graeffei didominasi oleh Diatom sebagai makanannya sedangkan pada jenis Holothuria scabra, Diatom merupakan makanan kedua terbesar setelah zooplankton. Dalam penelitian ini ditemukan dua genus dari ordo pennales yang lebih dominan dari genus lainnya yaitu Nitzschia dan Navicula.

IV. Penutup

4.1 Kesimpulan

Berdasarkan hasil penelitian maka dapat disimpulkan :

1. Ditemukan 6 jenis teripang berdasarkan identifikasi spikula yaitu Holothuria scabra, Holothuria atra, Holothuria nobilis, Holothuria axiologa, Bohadschia marmorata dan Bohadcshia graeffei.

2. Komposisi isi lambung teripang lebih didominasi oleh diatom bentik sebesar $56 \%$.

3. Hasil analisis frekuensi kejadian (Fr) ditemukan diatom bentik sebesar $78 \%$, jumlah lambung dengan makanan (f) sebesar $84 \%$ dan jumlah makanan dan jumlah total makanan dalam lambung (Cn) sebesar $43 \%$,

4.2. Saran

Diharapkan adanya penelitian lanjutan tentang aplikasi isi lambung teripang dalam pemeliharaan langsung di wadah terkontrol.

\section{DAFTAR PUSTAKA}

Effendie, M.I. 1979. Biologi Perikanan Penerbit Yayasan Pustaka Nusantara Yogyakarta. 163 hal.

Effendie, M.I. 2002. Biologi Perikanan (Edisi Revisi). Penerbit Yayasan Pustaka Nusantara Yogyakarta. 163 hal.

Hartati, R., Widianingsih dan D.Pringgenies. 2005. Teknologi Penyediaan Pakan Bagi Teripang Putih (Holothuria scabra). Laporan Kegiatan Penelitian Hibah Bersaing Universitas Diponegoro Semarang 
Huliselan, N.V. 2002. Diatom Bentik (Komposisi dan Distribusi) di Perairan Pantai Desa Naku Kodya Ambon-Maluku. Indonesian Journal of Marine Sciences Lembaga Penelitian Universitas Diponegoro Vol VII : 26.

Newel, G.E and R.C. Newel. 1977. Marine Plankton a Partical Guide. Fifth Editon. Hutchinson Education. 244 pp.

Padang, A. 2009. Struktur Komunitas Diatom Bentik dan Hubungannya dengan Karakteristik Sedimen di Teluk Ambon Dalam (Tesis Pada Pascasarjana Universitas Pattimura Ambon,104 hal, tidak dipublikasikan).

Padang, A. 2010. Struktur Komunitas Diatom Bentik pada Ekosistem Lamun. Penelitian Mandiri.

Padang, A. 2011. Struktur Komunitas Diatom Bentik Pada Komunitas Lamun. (Penelitian dibiayai oleh DIPA Kopertis Wilayah XII Tahun Anggaran 2011)

Padang, A. 2011. Komposisi Diatom Bentik pada Sedimen di Ekosistem Lamun. Dalam : Jurnal BIMAFIKA Fakultas Keguruan dan Ilmu Pendidikan Universitas Darussalam, ISSN: 2086 1869 Volume. 3, No. 2 November 2011. Hal: 272-278

Padang, A.2012. Peranan Diatom Bentik Bagi Produktivitas Primer di Lingkungan Bentik Jurnal BIMAFIKA Fakultas Keguruan dan Ilmu Pendidikan Universitas Darussalam, ISSN: 2086 1869. Volume 4 No. 1 Bulan November 2012 Hal 420-424Organisme

Romimohtarto, K dan S.Juwana. 2007. Biologi Laut Ilmu Pengetahuan tentang Biota Laut. Penerbit Djambatan Jakarta. 540 hal.

Sofyan, Y., B.Irwansyah., Sukriadi., Adeyana., D.K.Wibawa. 2005. Pembenihan Abalone (Haliotis asinina) di Balai Budidaya Laut Lombok. Departemen Kelautan dan Perikanan Budidaya Balai Budidaya Laut Lombok. 30 hal.

Sumich, J.L. 1999. An Introduction to the Biology of Marine Life. WBC/MC Grow-hill.

Sutaman. 1993. Petunjuk Praktis Budidaya Teripang. Penerbit Kanisius. Yogyakarta.

Tomas, C.R. 1997. Identifying Marine Phytoplankton. Academic Press Harcourt Brace \& Company. 857 pp.

Yamaji, E. E. 1966. The Ilustration of Marine Plankton of Japan Hoikusha, Osaka, Japan, Third edition. 536 pp.

Yusron, E dan D.S.Syafei, 1997. Studi Analisis Makanan dari Beberapa Jenis Teripang (Holothuroidea) di Perairan Pulau Ambon. Prosiding II Seminar Nasional Biologi XV. ISBN : 979-8287-17-7, Hal :781-785

Van Heurck, H. 1962. Wheldon \& Wesley, LTD and Verlag J. Cramer. 